\title{
Mechanical Properties of Melt-Spun Amorphous Ni-Nb-Zr Alloys after Hydrogen Charging
}

\author{
Asahi Kawashima, Shinji Yamaura, Naofumi Ohtsu, Hisamichi Kimura and Akihisa Inoue \\ Institute for Materials Research, Tohoku University, Sendai 980-8577, Japan
}

The effect of pre-charged hydrogen on the mechanical behavior of melt-spun amorphous Ni-Nb-Zr alloys was investigated. A substantial increase in the tensile fracture strength is observed even in hydrogen content up to about 46 at $\%$. The Vickers hardness gradually increases with an increase in hydrogen content up to about 27 at $\%$, and keeps almost the same value in the higher content more than 46 at $\%$. It might be said that the amorphous $\left(\mathrm{Ni}_{0.6} \mathrm{Nb}_{0.4}\right)_{70} \mathrm{Zr}_{30}$ alloy is not embrittled distinctly even in the high hydrogen content at room temperature. The amorphous alloy ribbons always curled during hydrogenation and the outer side of the curled ribbon corresponds to the roll side due to preferential absorption of hydrogen. XPS study revealed that the zirconium content in the surface film of the roll side surface is lower than that of the top side surface. The difference in surface composition as well as higher surface roughness of the roll side surface seems responsible for the preferential hydrogen absorption. [doi:10.2320/matertrans.47.1523]

(Received February 27, 2006; Accepted April 13, 2006; Published June 15, 2006)

Keywords: amorphous nickel-niobium-zirconium alloys, mechanical properties, hydrogen embrittlement, melt-spinning

\section{Introduction}

In recent years, the development of hydrogen purification techniques has been strongly required to increase the lifetime and efficiency of electric power generation of fuel cell. There are various hydrogen purification techniques, such as the pressure swing adsorption, cryogenic separation and the membrane separation. One of them, the separation technique using a hydrogen permeable membrane, is simpler and more suitable for mass-production. The metallic membrane is regarded as the preferable one because of its high thermal stability and excellent hydrogen selectivity. However, the membrane alloy in current use has been limited to the palladium-silver system. ${ }^{1)}$ Since palladium metal is very expensive, it is desirable to develop a new membrane alloy with minimum addition of palladium metal or without it. Some of the present authors have developed the amorphous $\mathrm{Ni}-\mathrm{Nb}-\mathrm{Zr}$ alloys, and reported that the melt-spun amorphous $\left(\mathrm{Ni}_{0.6} \mathrm{Nb}_{0.4}\right)_{70} \mathrm{Zr}_{30}$ alloy possesses excellent hydrogen permeability of $1.3 \times 10^{-8} \mathrm{~mol} \mathrm{~m}^{-1} \mathrm{~s}^{-1} \mathrm{~Pa}^{-1 / 2}$ at $673 \mathrm{~K}$. The permeability increases with an increase in zirconium content. ${ }^{2,3)}$ These facts indicate a possibility of future practical use of the melt-spun alloys as a hydrogen permeable membrane. However, it was also shown that the embrittlement of these alloys became significant during permeation test. The requirements for the hydrogen permeable membranes are not only high hydrogen permeability but also excellent immunity from hydrogen embrittlement (HE) ${ }^{4)} \mathrm{HE}$ of metal-metalloid amorphous alloys based on iron and nickel has been observed after or during cathodic polarization. $^{5-9)}$ Recently, that of metal-metal metallic glasses, such as $\mathrm{Zr}-\mathrm{Ti}-\mathrm{Ni}-\mathrm{Cu}-\mathrm{Be}^{10)}$ and $\mathrm{Ti}-\mathrm{Ni}-\mathrm{Cu}^{11)}$ has been reported. In the Zr-based metallic glass, an increase of flow stress and degradation of fracture toughness were observed. On the other hand, the Ti-based ones showed a gradual decrease in fracture strength after absorbing hydrogen. Accordingly, the influence of hydrogen on the mechanical properties is different depending on the alloy system. In comparison of $\mathrm{Fe}-$, Ti- and $\mathrm{Zr}$-based amorphous alloys, investigation on the mechanical properties of hydrogenated Ni-based metal-metal amorphous alloys has been considerably less.

The purpose of this work is to investigate the hydrogen absorption behavior and the effect of hydrogen on the mechanical properties of the amorphous $\mathrm{Ni}-\mathrm{Nb}-\mathrm{Zr}$ alloys.

\section{Experimental Procedures}

The rotating wheel method under an argon atmosphere was used for the preparation of amorphous $\left(\mathrm{Ni}_{0.6} \mathrm{Nb}_{0.4}\right)_{100-x} \mathrm{Zr}_{x}$ $(x=30$ and 50 at $\%)$ alloy ribbons of about $0.5-1 \mathrm{~mm}$ width and $16-25 \mu \mathrm{m}$ thickness from argon arc-melted ingots. Hydrogen charging was made electrolytically in $0.5 \mathrm{M}$ $\mathrm{H}_{2} \mathrm{SO}_{4}+1.4 \mathrm{~g} / \mathrm{L}$ thiourea $\left(\mathrm{H}_{2} \mathrm{NCSNH}_{2}\right)$ at room temperature and at the current densities of 200 and $500 \mathrm{~A} / \mathrm{m}^{2}$. The amounts of hydrogen absorbed in the specimens were measured by the inert gas carrier melting-thermal conductivity method.

Tensile fracture strength of hydrogenated specimens was measured at room temperature in air by using an Instron-type tensile testing machine at a strain rate of $8.3 \times 10^{-4} \mathrm{~s}^{-1}$. Hardness (Hv) measurements were carried out by a Vickers microhardness tester with a $50 \mathrm{~g}$ load. The alloy structure was identified by X-ray diffraction with $\mathrm{Cu} K \alpha$ radiation at grazing incident mode. The angle of incident used was $2^{\circ}$.

XPS measurements were carried out to analyze the surface composition of the specimen before and after hydrogenation by using a SSI SSX-100 photoelectron spectrometer with Al $\mathrm{K} \alpha$ excitation $(\mathrm{h} v=1486.6 \mathrm{eV})$. The composition of surface films of the roll and top side surfaces of the alloy ribbon was quantitatively determined by a previously proposed method using integrated intensities of photoelectron peaks. ${ }^{12)}$

\section{Results and Discussion}

Figure 1 shows typical XRD patterns of amorphous $\left(\mathrm{Ni}_{0.6} \mathrm{Nb}_{0.4}\right)_{70} \mathrm{Zr}_{30}$ alloy ribbons before and after hydrogen charging. Only a broad diffraction peak was observed for all specimens. Similar result was obtained for amorphous 


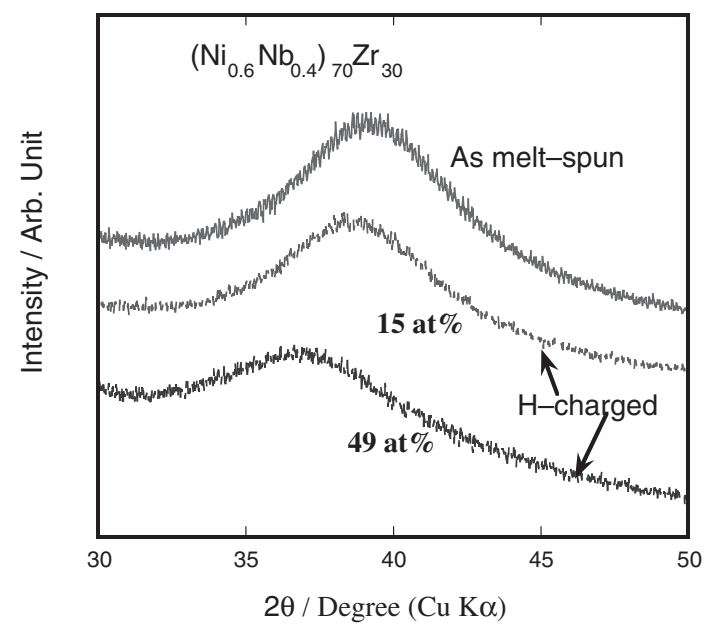

Fig. 1 XRD patterns for the hydrogenated amorphous $\left(\mathrm{Ni}_{0.6} \mathrm{Nb}_{0.4}\right)_{70} \mathrm{Zr}_{30}$ alloy.

$\left(\mathrm{Ni}_{0.6} \mathrm{Nb}_{0.4}\right)_{50} \mathrm{Zr}_{50}$ alloy ribbon. This indicates that the meltspun alloys consist of a single amorphous phase even after heavy hydrogenation up to about 49 at $\%$. It is not shown here but for the specimen containing 55 at\% hydrogen, the same result was obtained. The halo peak shifted to the lower angle with increasing hydrogen content, indicating that the volume expansion occurs as shown in the other amorphous alloys. ${ }^{6,10,11)}$ It should be noted that the morphology of the amorphous ribbons was changed after electrolytic hydrogenation. Figure 2 shows a change in the outer appearance of the hydrogenated $\left(\mathrm{Ni}_{0.6} \mathrm{Nb}_{0.4}\right)_{70} \mathrm{Zr}_{30}$ alloy ribbon (hydrogen content of about 15 at $\%$ ) stored in air at room temperature for various periods of time. Considering that the outer side in the curled ribbon specimen always corresponds to the rollercontacted side (roll side), the absorption of hydrogen probably takes place preferentially from the roll side surface.
The curled specimen tends to return the originally straight shape as the aging time increases (Figs. 2(b), (c), (d)) by the homogenization of hydrogen distribution in the ribbon. The preferential absorption of hydrogen at the roll side surface is presumably due to an ease of adsorption of hydrogen atoms resulting from higher degree of activity and surface roughness on the roll side surface. The melt-spinning produces the relatively deep gas entrainment furrows on the roll side, resulting in an increase in surface roughness. The activity of adsorption and absorption of hydrogen may depend on the surface composition. Accordingly the surface composition was measured by using XPS. XPS spectra from the alloy exhibited nickel, niobium, zirconium, oxygen and carbon. The C 1s peak arose from a contaminant hydrocarbon layer covering the specimen surface. The oxidized states of nickel, niobium and zirconium were assigned to $\mathrm{Ni}^{2+}, \mathrm{Nb}^{5+}$ and $\mathrm{Zr}^{4+}$, respectively. Figure 3 shows the atomic concentration of surface oxide film before and after hydrogenation formed on the top and roll side surfaces of amorphous $\left(\mathrm{Ni}_{0.6} \mathrm{Nb}_{0.4}\right)_{70} \mathrm{Zr}_{30}$ alloy ribbon. It is clear that the surface composition of the alloy after hydrogenation is almost the same as that of as-received specimen. That is, the air-formed film is very stable and not reduced even after severe cathodic polarization at $500 \mathrm{~A} / \mathrm{m}^{2}$ for $25.2 \mathrm{ks}$. The XPS study also revealed the enrichment of $\mathrm{Zr}^{4+}$ in both top and roll side surfaces compared with the bulk alloy composition, while niobium content is similar level to the bulk alloy composition. Nickel does not virtually exist in the surface film possibly due to lower oxidizing ability than niobium or zirconium. It is noted that the zirconium content in the top side surface is larger than that in the roll side one. Yamaura et al. ${ }^{13)}$ previously measured the hydrogen content in the cathodically charged amorphous $\mathrm{Ni}-\mathrm{Nb}-\mathrm{Zr}$ alloys, and found that the hydrogen absorption rate of the specimen is higher with decreasing zirconium content from 50 to 30 at $\%$.

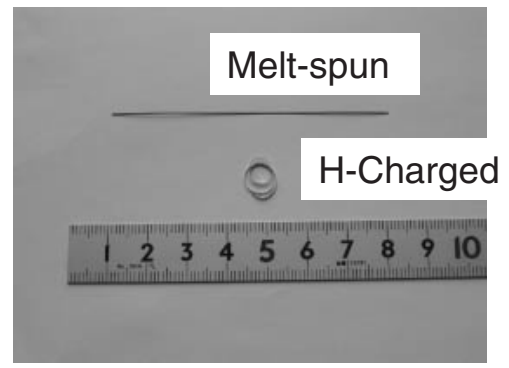

(a) $600 \mathrm{~s}$

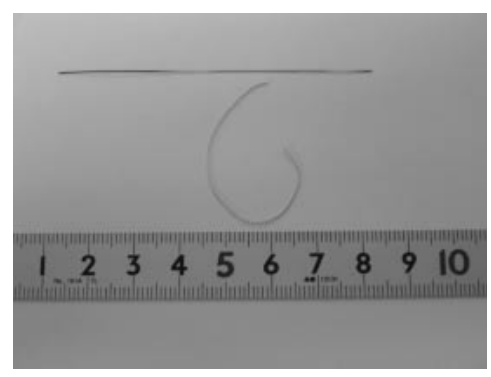

(c) $27 \mathrm{ks}$

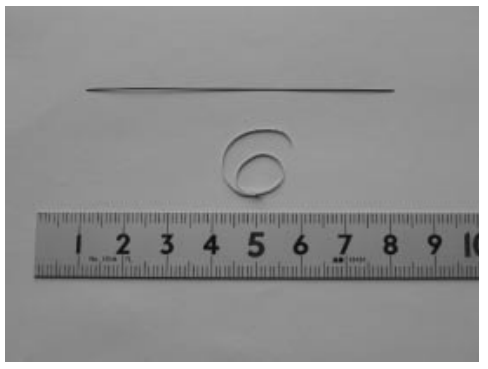

(b) $12.6 \mathrm{ks}$

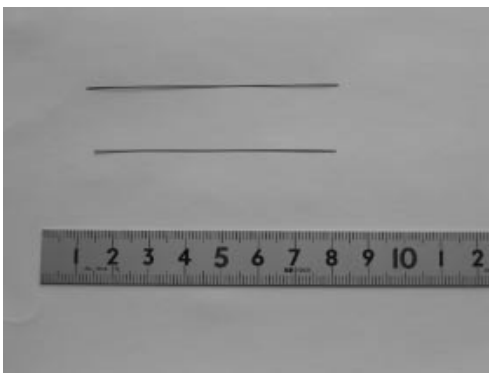

(d) $864 \mathrm{ks}$

Fig. 2 Change in the morphology of amorphous $\left(\mathrm{Ni}_{0.6} \mathrm{Nb}_{0.4}\right)_{70} \mathrm{Zr}_{30}$ alloy ribbon after hydrogen charging with aging time in air. 


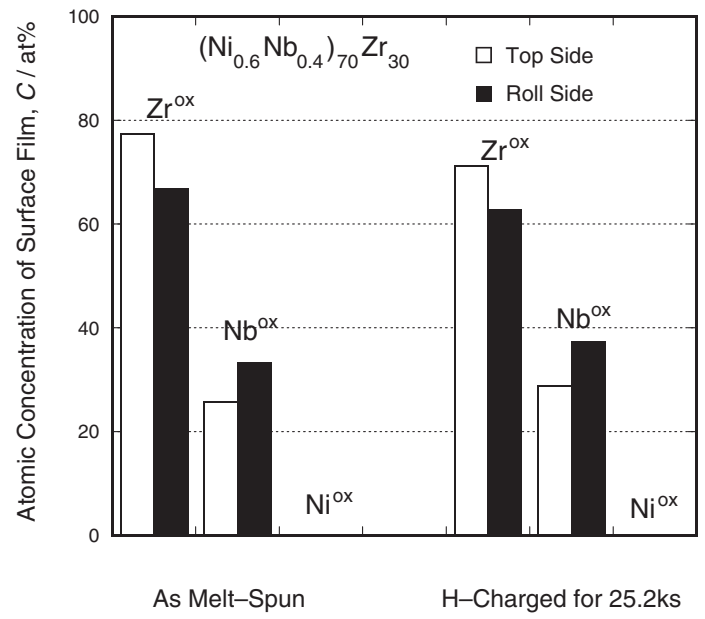

Fig. 3 Change in surface concentration on top and roll side surfaces for the amorphous $\left(\mathrm{Ni}_{0.6} \mathrm{Nb}_{0.4}\right)_{70} \mathrm{Zr}_{30}$ alloy.

Kawashima et $a l .{ }^{14)}$ investigated the electrochemical polarization behavior of amorphous $\mathrm{Ni}-\mathrm{Zr}$ alloys in a $0.5 \mathrm{M} \mathrm{H}_{2} \mathrm{SO}_{4}$ solution, and concluded that the alloys with lower zirconium content showed higher cathodic activity, corresponding to higher hydrogen absorption rate. ${ }^{15)}$ Therefore, it is concluded that the absorption of hydrogen takes place preferentially from the roll side surface, resulting in the change in the appearance after hydrogenation, as shown in Fig. 2.

Figure 4 illustrates examples of nominal tensile stress vs. strain curves for the amorphous $\left(\mathrm{Ni}_{0.6} \mathrm{Nb}_{0.4}\right)_{70} \mathrm{Zr}_{30}$ alloy ribbon at the strain rate of $8.3 \times 10^{-4} \mathrm{~s}^{-1}$. The strain shows a nonlinear increase with increasing stress after hydrogen charging and the stress vs strain data show $\mathrm{S}$ like curve. It is clearly understood from this figure that the tensile fracture strength and fracture elongation increase with an increase in hydrogen content in the alloy. Similar result was obtained for the amorphous $\left(\mathrm{Ni}_{0.6} \mathrm{Nb}_{0.4}\right)_{50} \mathrm{Zr}_{50}$ alloy. Figures $5(\mathrm{a})$ and $(\mathrm{b})$ show the tensile fracture strength and Vickers microhardness as a function of hydrogen content in the amorphous $\left(\mathrm{Ni}_{0.6} \mathrm{Nb}_{0.4}\right)_{70} \mathrm{Zr}_{30}$ alloy. A substantial increase of the fracture strength as a function of the hydrogen content is observed up to about 46 at $\%$. The microhardness gradually increases with an increase in hydrogen content up to about 27 at $\%$, and keeps almost the same value in the higher content more than 46 at $\%$. In the hydrogen content more than about 50 at $\%$, the

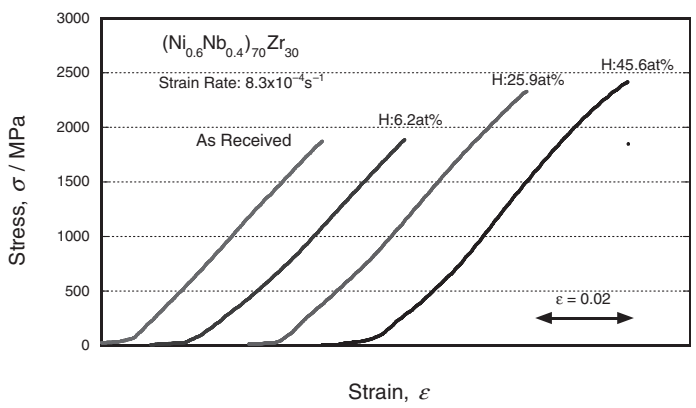

Fig. 4 Tensile stress vs strain curves for the amorphous $\left(\mathrm{Ni}_{0.6} \mathrm{Nb}_{0.4}\right)_{70} \mathrm{Zr}_{30}$ alloy ribbon as a function of hydrogen content at the strain rate of $8.3 \times 10^{-4} \mathrm{~s}^{-1}$.

fracture strength varies from 730 to $2440 \mathrm{MPa}$. A noteworthy finding is the increase of tensile fracture strength for the specimen even in higher hydrogen content up to about 46 at $\%$. Similar increase in the fracture strength has been reported for the amorphous $\mathrm{Zr}-\mathrm{Cu}-\mathrm{Al}$ and $\mathrm{Zr}-\mathrm{Cu}-\mathrm{Al}-\mathrm{Si}$ alloys ${ }^{16,17)}$ with hydrogen content up to about 20 at\%. Ti$\mathrm{Ni}-\mathrm{Cu}$ metallic glasses showed a gradual decrease in fracture strength after absorbing hydrogen up to about 25 at $\%$, and it decreased significantly in the higher hydrogen content beyond 30 at $\%{ }^{11)}$ For Fe-metalloid amorphous alloys, the fracture strength decreases with an increase in hydrogen content. They become brittle even in a small amount of hydrogen below about 5 at $\% .{ }^{18)}$ From these results, it might be concluded that the amorphous $\left(\mathrm{Ni}_{0.6} \mathrm{Nb}_{0.4}\right)_{70} \mathrm{Zr}_{30}$ alloy is not embrittled distinctly even in the higher hydrogen content at room temperature. The mechanism of the increase in the fracture strength and embrittlement after hydrogenation is not clear at the present stage. Generally, the deformation in amorphous alloy occurs in highly inhomogeneous shear band and the fracture occurs along the resulting shear plane. ${ }^{19)}$ Deformation and fracture in amorphous alloys are closely related to both microstructure and interstitial atoms. Accordingly, further work is needed in the fundamental nature of the interaction between hydrogen and amorphous microstructure.

\section{Conclusions}

Influence of hydrogen on the mechanical properties of the
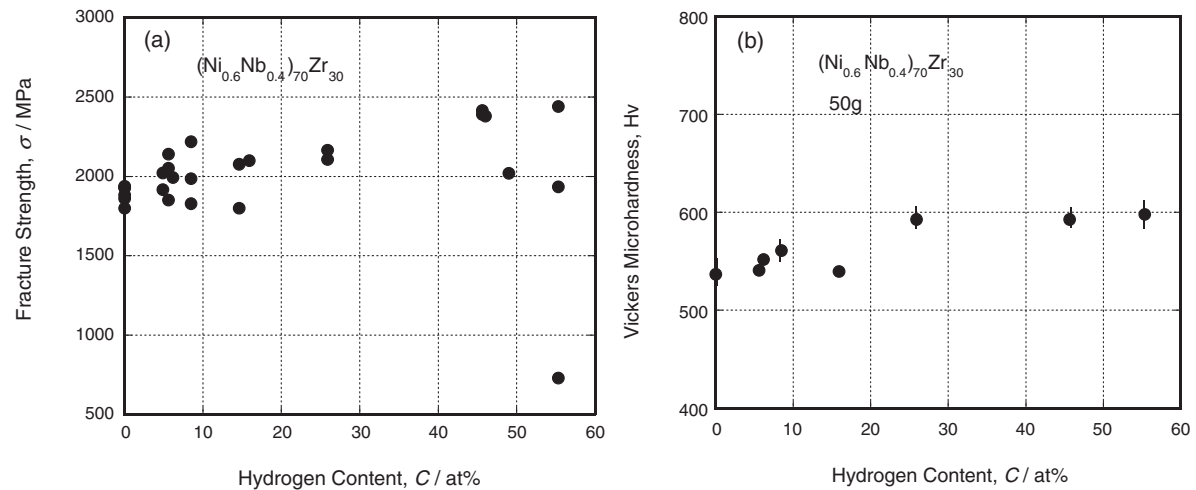

Fig. 5 (a) Tensile fracture strength and (b) Vickers hardness for the amorphous $\left(\mathrm{Ni}_{0.6} \mathrm{Nb}_{0.4}\right)_{70} \mathrm{Zr}_{30}$ alloy ribbon as a function of hydrogen content. 
amorphous $\left(\mathrm{Ni}_{0.6} \mathrm{Nb}_{0.4}\right)_{100-x} \mathrm{Zr}_{x}(x=30$ and 50 at\%) alloy ribbons was examined. The results obtained are as follows.

The amorphous alloys consist of a single amorphous phase even after heavy hydrogenation up to about 55 at $\%$. The volume expansion in the specimen occurs owning to hydrogen absorption.

The amorphous alloy ribbons always curled during hydrogenation and the outer side of the curled ribbon corresponds to the roll side due to preferential absorption of hydrogen. XPS study revealed that the zirconium content in the surface film of the roll side surface is lower than that of the top side surface. The difference in surface composition as well as higher surface roughness of the roll side surface seems responsible for the preferential hydrogen absorption.

The tensile fracture strength increases with an increase in the hydrogen content up to about 46 at $\%$ and the Vickers hardness gradually increases with hydrogen content up to about 27 at $\%$ and keeps almost the same value in the higher content more than 46 at\%.

\section{Acknowledgments}

The authors wish to thank Mr. K. Sasamori and Mr. Y. Murakami for tensile testing and XRD measurements. This work was financially supported in part by Grant-in-Aid for Scientific Research on Priority Area "Materials Science of Bulk metallic Glasses", and by Research and Development Project on Advanced Metallic Glasses, Inorganic Materials and Joining Technology from the Ministry of Education, Culture, Sports, Science and Technology of Japan.

\section{REFERENCES}

1) S. Uemiya, N. Sato, H. Ando, Y. Kude, T. Matsuda and E. Kikuchi: J. Membr. Sci. 56 (1991) 303-313.

2) S. Yamaura, Y. Shinpo, H. Okouchi, M. Nishida, O. Kajita, H. M. Kimura and A. Inoue: Mater. Trans. 44 (2003) 1885-1890.

3) H. M. Kimura, A. Inoue, S. Yamaura, K. Sasamori, M. Nishida, Y. Shinpo and H. Okouchi: Mater. Trans. 44 (2003) 1167-1171.

4) C. Nishimura, M. Komaki, S. Hwang and M. Amano: J. Alloy Compd. 330-332 (2002) 902-906.

5) A. Kawashima, K. Hashimoto and T. Masumoto: Corros. Sci. 16 (1976) 935-943.

6) M. Nagumo and T. Takahashi: Mater. Sci. Engng 23 (1976) 257-259.

7) A. Kawashima, K. Hashimoto and T. Masumoto: Corrosion. 36 (1980) 577-583.

8) J. Flis, S. Ashok, N. S. Stoloff and D. J. Duquette: Acta Metall. 35 (1987) 2071-2079.

9) Y. Zuo and R. M. Latanision: Mater. Sci. Engng. A159 (1992) 87-94.

10) D. Suh and R. H. Dauskardt: Scripta Mater. 42 (2000) 233-240.

11) S. Yamaura, M. Hasegawa, H. M. Kimura and A. Inoue: Mater. Trans. 43 (2002) 2543-2547.

12) K. Asami and K. Hashimoto: Corros. Sci. 24 (1984) 83-97.

13) S. Yamaura, M. Sakurai, M. Hasegawa, K. Wakoh, Y. Shinpo, M. Nishida, H. M. Kimura, E. Matsubara and A. Inoue: Acta Mater. 53 (2005) 3703-3711.

14) A. Kawashima, W.-P. Yu, B.-P. Zhang, H. Habazaki, K. Asami and K Hashimoto: Mater. Trans. JIM: 38 (1997) 443-450.

15) A. Kawashima, K. Hashimoto and S. Shimodaira: Corrosion 32 (1976) 321-332.

16) H. Mizubayashi, Y. Ishikawa and H. Tanimoto: Mater. Trans. 43 (2002) 2662-2669.

17) H. Mizubayashi, Y. Ishikawa and H. Tanimoto: J. Alloys Compd. 355 (2003) 31-36.

18) T. Yamazaki, K. Nagasawa, Y. Ogino, A. Kawashima and K. Hashimoto: J. Japan Inst. Metals 55 (1991) 646-653.

19) H. S. Chen, H. J. Leamy and M. J. O’Brien: Scripta Met. 7 (1973) 415419. 